\title{
Screening for Helicobacter Pylori Infection among Undergraduate Students of a Tertiary Institution using serum Antibody and Stool Antigen Detection Methods
}

\author{
Enitan Seyi Samson ${ }^{1 *}$, Ochei John Okeleke ${ }^{1}$, Akele Yomi Richard ${ }^{2}$, Faloye Taiwo Gideon¹, Adeniyi Lydia \\ Olutoyosi ${ }^{1}$ and Omotola Damilola ${ }^{1}$
}

${ }^{1}$ Department of Medical Laboratory Science, Babcock University, Nigeria

${ }^{2}$ Department of Medical Laboratory Science, Afe Babalola University, Nigeria

Received: February 01, 2018; Published: March 23, 2018

*Corresponding author: Enitan Seyi Samson, Department of Medical Laboratory Science, Babcock University, Ilishan-Remo, Nigeria, Email: enitans@babcock.edu.ng

Abstract

Helicobacter Pylori infection has been identified as an important risk factor for the development of peptic ulcer disease (PUD). The aim of this study is to determine the prevalence of $\mathrm{H}$. pylori infection and associated risk factors among undergraduate students of Babcock University. The serum and stool samples of 200 participants ( 85 males and 115 females) were randomly collected and screened using H. pylori antibody/ antigen test Cassettes supplied by Blue Cross Bio-Medical, Beijing, China. The demographic and clinical information of the participants were also collected using a structured questionnaire. The outcome of the study show that out of the 200 participants screened, 56 (28.0\%) were positive for Helicobacter Pylori serum antibody, while 47 (23.5\%) were positive for Helicobacter Pylori stool antigen. Of the 85 male students tested, $7(8.2 \%)$ tested positive for the serum antibody, while $6(7.1 \%)$ were positive for the stool antigen. On the other hand, 49 (42.6\%) out of the 115 female students tested were positive for the serum antibody, while 41 (35.7\%) were positive for the stool antigen. Prevalence of Helicobacter Pylori infection was found to be significantly higher $(\mathrm{P}<0.05)$ among female participants than their male counterparts.

On the basis of age, the prevalence of Helicobacter Pylori infection was found to be significantly higher $(\mathrm{P}<0.05)$ among participants that were 21-25 years old when compared to other age groups. With regard to clinical indications of PUD, 108 (54.0\%) of the participants were asymptomatic, out of which 20 (37.0\%) of them were positive for Helicobacter Pylori serum antibody, while 18 (17.0\%) were positive for the stool antigen. Symptomatic participants complained mostly of heart burn, followed by loss of appetite, abdominal pain, nausea, dark foulsmelling stool and lastly, vomiting. Howbeit, none of them complained of vomiting blood. Identifiable risk factor associated with infection include: past history of $\mathrm{H}$. pylori infection/gastric diseases, drinking of raw cow milk, consumption of beef, fish, poultry products, vegetables and fruits. This study provides data on the existence of Helicobacter Pylori infection among students of Babcock University, hence the need for public awareness and clinical management in this regard.

Keywords: Helicobacter Pylori; Peptic Ulcer Disease; Risk Factors; Serum Antibody; Stool Antigen

Abbreviations: PUD: Peptic Ulcer Disease; NSADIs: Non-Steroidal Anti-Inflammatory Drugs; BUHREC: Babcock University Health Research Ethics Committee; PIDN: Participant Identification Number; PCR: Polymerase Chain Reaction

\section{Introduction}

Helicobacter Pylori (H. pylori) previously named Campylobacter pylori, is a spiral, flagellated Gram negative, microaerophilic bacterium found in the stomach with a capability for abundant urease production which has been implicated in several upper gastrointestinal diseases that present dyspepsia [1]. It was the first formally recognized bacterial carcinogen and one of the most successful human pathogens, which has been etiologically associated with gastritis and gastritis associated diseases, peptic ulcer, gastric adenocarcinoma and primary gastric lymphoma [2].
Previous research has shown that Helicobacter Pylori are present in patients with chronic gastritis, duodenal ulcers, conditions not previously believed to have a microbial cause [3]. H. pylori infection has been identified as an important risk factor for the development of peptic ulcer disease (PUD) and is probably the most important cause of relapse in those previously treated for peptic ulcer disease [4].

According to Nwodo et al. [5], H. pylori infection may lead to acute gastritis (abdominal pain, nausea and vomiting) within two 
weeks following infection. Many patients infected with the organism have recurrent abdominal symptoms (non-ulcer dyspepsia) without ulcer disease. Duodenal inflammation (duodenitis) also often occurs, as well as peptic ulcer. These are sores that develop in the lining of the stomach, lower oesophagus, or duodenum: gastric ulcers, oesophageal ulcers and duodenal ulcers respectively [6]. Common risk factors for peptic ulcer disease include: Helicobacter Pylori infection and non-steroidal anti-inflammatory drugs (NSAIDs). The less common risk factors include alcohol, smoking, cocaine, severe illness, autoimmune problems, radiation therapy and Crohn's disease among others [7]. Furthermore, peptic ulcer disease is one of the most common human ailments, affecting approximately $50 \%$ of the world population [7]. The most common symptom of peptic ulcer is burning abdominal pain that extends from the navel to the chest, which can range from mild to severe. Other symptoms include; changes in appetite, nausea, blood or dark stool (melena), indigestion, vomiting and weight loss [6].

Complications of peptic ulcer disease include bleeding, perforation, gastric outlet obstruction and gastric cancer. Older persons are at higher risk of peptic ulcer disease because of high-risk medication use, including anti-platelet drugs, warfarin, selective serotonin, proton pump inhibitors and bisphosphonates [8]. The prevalence of $H$. pylori infection varies between and within countries in relation with age, race, ethnicity, and geographical area of the population [2]. Infections are usually acquired in early childhood in most countries [9]. The infection rate of children in developing nations is higher than in industrialized nations, probably due to poor sanitary conditions, perhaps combined with lower antibiotics usage for unrelated pathologies [3]. H. pylori infection is common worldwide with prevalence rates ranging from 30 to $40 \%$ in the United States, 80 to $90 \%$ in South America and 70 to $90 \%$ in Africa. It is more common in developing countries, and its prevalence increases with age from $20 \%$ among teenagers to 50 to $60 \%$ of subjects in the 6 th and 7 th decades of life [10]. In a hyperendemic area like Nigeria, the determination of the true prevalence of Helicobacter Pylori infection is best done with the use of biopsy based methods, but for the purpose of epidemiological survey, rapid and easy screening for $H$. pylori infection can be achieved with the use of serological tests, despite their low discriminatory power between previous and current infections [1].

According to Fashner and Gitu [8], urea breath tests and stool antigen tests are most accurate for identifying Helicobacter Pylori infection and can be used to confirm cure. In addition, patient's serum could also be tested for the presence of anti- $H$. pylori antibody. Over $50 \%$ of the world's population, especially children and youths harbour $H$. pylori in their upper gastrointestinal tract. Infection is more prevalent in developing countries. However, the level of awareness of this bacterium, as a causative agent of peptic ulcer disease appears to be very low among students population. Early detection of $H$. pylori infection might prevent peptic ulcer disease and its complications. Howbeit, the percentage occurrence of $H$. pylori infection among undergraduate students of Babcock University is not known. Besides, there is need to identify factors that pre-dispose young adults in this setting to $H$. pylori infection.
Scarcity of information in this regard, therefore necessitates this study. The aim of this study is therefore to determine the prevalence of Helicobacter Pylori infection and associated risk factors among undergraduate students of Babcock University using serum antibody and stool antigen detection methods.

\section{Materials and Methods}

Study Area: This descriptive institutional based study was carried out among undergraduate students of Babcock University, Ilishan-Remo, Ogun State, a first class Seventh-day Adventist Institution of higher learning located in the South-Western region of Nigeria, coordinates: 6.8862o N, 3.7055o E. The University has nine (9) schools with a total student population of about six thousand (6, 000) offering different academic and professional courses.

Duration of Study: The study was carried between the months of March and May, 2017.

Study Population: Undergraduate students in Babcock University consist of young male and female adults within the age range of 16-35 years from different ethnic, religious and cultural background; studying different courses in various departments.

Sample Size Calculation: The sample size (n) was estimated using the formula:

$$
n=(1.96)^{2} p q / d^{2}
$$

Where;

$\mathrm{n}=$ required sample size,

$\mathrm{p}=$ proportion of the population having H. pylori infection from previous study,

$\mathrm{q}=1-\mathrm{p}$ and

$\mathrm{d}=$ the degree of precision

For the calculation, a 95\% confidence interval, a p value of 0.865 , i.e., a prevalence rate of $86.5 \%$ from previous study by Ejilude et al. [11] and margin of error (d) set at 0.05 was used to determine the minimum sample size required. To minimize errors arising from the likelihood of non-compliance, $10 \%$ of the sample size was added giving a final sample size of 200.

Sample Size: A total of 200 blood and stool specimens were collected randomly from interested 200 undergraduate students (85 males and 115 females) of Babcock University, Ilishan-Remo, and Ogun state.

Ethical Consideration: Ethical approval for the study was obtained from Babcock University Health Research Ethics Committee (BUHREC) before commencing the study.

\section{Eligibility of Subjects:}

a) Inclusion criteria: Undergraduate students without history of antibiotic therapy, pain medication (NSAID), antiplatelet drug, physiological anticoagulant, selective serotonin, proton pump inhibitors and bisphosphonates in the preceding two weeks were recruited randomly for the study. 
b) Exclusion criteria: Undergraduate students with the history of antibiotic therapy, pain medication (NSAID), antiplatelet drug, Physiological anticoagulant, selective serotonin, proton pump inhibitors, and bisphosphonates in the preceding two weeks, as well as Postgraduate students were excluded from the study.

c) Consent: Informed consent was obtained from each willing participant whose blood and stool specimen was used for the study. The objectives, benefits and procedure for the study was made very clear to the participants and they were assured of the confidentiality and voluntariness associated with the study.

d) Datacollection: Priorto specimen collection, demographic and clinical information of the participants was obtained using prepared questionnaires which was administered to the participants. Each questionnaire had a unique participant identification number (PIDN). Data collection lasted for an average of 7 days in the study location. This period was used for the selection of the subjects, distribution and retrieval of the questionnaires, and collection of samples. The pre-test questionnaires were administered to the participants directly. The first part of the questionnaires contained the biodata of the participants such as age, marital status, study level and tribe. The second part included clinical data relating to history of gastrointestinal disease (epigastric abdominal pain, bloating, water brash, gastroesophageal reflux, nausea, vomiting, loss of appetite, hematemesis, melana, heart burn etc), risk factors (if any), personal hygiene and health care-seeking behaviour. The study population was stratified by study level (100, 200, 300, 400 and 500 levels). Al filled questionnaires were examined for completeness daily and stored securely in a locker. Data entries were done on the following day. For each participant, only the PIDN was recorded on the laboratory forms (no names) for the purpose of confidentiality. All the filled questionnaires were destroyed after data entry had been completed.

e) Specimen Collection: Both blood and stool specimens were collected from each participant.

f) Venous Blood Collection: Two (2) $\mathrm{ml}$ of venous blood sample was collected into plain bottles and allowed to clot to get the sera. Following blood clotting, the serum was separated by aspiration using Pasteur pipette.

g) Stool Specimen Collection: Self-collected stool specimen was requested from each participant. They were given sterile leak proof single use universal bottle with a screw-capped lid, as well as instruction on how to collect their stool specimen aseptically in private.

h) Specimen Storage: The blood and stool specimens were transported to the Laboratory Unit of the Department of Medical Laboratory Science, Babcock University and processed within 2 hours, otherwise the sera was stored at 2-8oC for up to 3 days. For long term storage, specimen was kept below -20oC. Frozen specimens were completely thawed and mixed well prior to testing. Repeated cycle of freezing and thawing of sera was avoided. The stool specimens on the other hand were stored at $4 \mathrm{oC}$ in the refrigerator if delay was also expected.

\section{Laboratory Analyses:}

a) Detection of Serum Anti-Helicobacter Pylori Antibody: Serum anti-Helicobacter Pylori antibody was detected using a one-step H. pylori antibody test cassette supplied by Blue Cross Bio-Medical Co., Ltd., Beijing, China according to the manufacturer instruction.

b) Detection of Stool Helicobacter Pylori Antigen: Stool Helicobacter Pylori antigen was detected using a one-step $H$. pylori antigen test cassette supplied by Blue Cross BioMedical Co., Ltd., Beijing, China according to the manufacturer instruction.

c) Interpretation of the Test: The presence of two color bands (Test - "T" band and Control - "C" band) within the result window regardless of which band appeared first indicated a positive result. The presence of only one pink color band within the result window indicated a negative result. The test was invalid if control line fails to appear. If there was no distinct color visible both in the test and control region, or there was a visible line only in the test region but not control region, then the test was considered invalid and the specimen retested (Figures 1 \& 2).

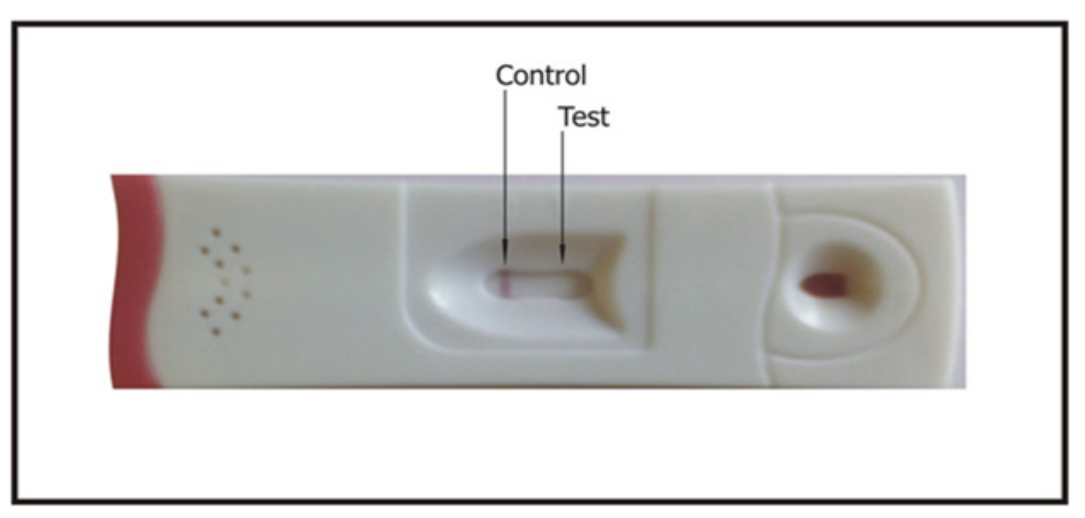

Figure 1: Picture showing a serum antibody test negative for Helicobacter pylori. 


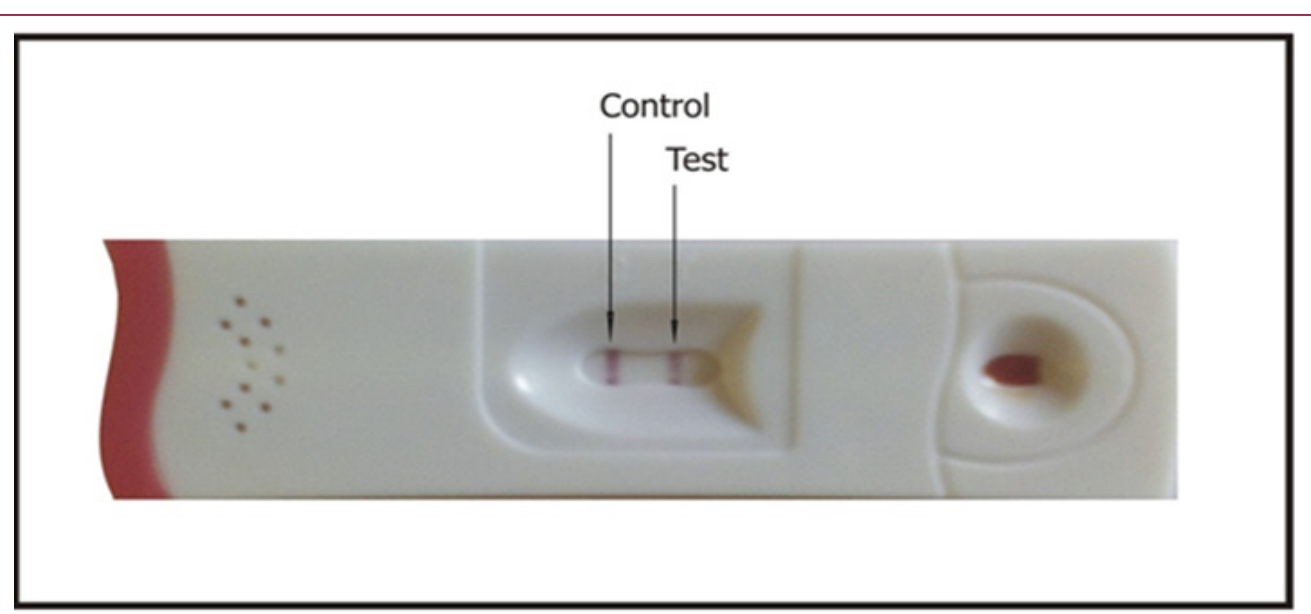

Figure 2: Picture showing a serum antibody test positive for Helicobacter pylori.

\section{Data Analysis}

Data obtained for the serum antibody and stool antigen screening were presented using tables and was analysed with one way analysis of variance (ANOVA) and Tukey-Kramer Multiple Comparisons Test using SPSS-18.0 (Statistical packages for social Scientists - version 18.0) statistical program. P values $<0.05$ was considered significant [12].

\section{Results}

The present study investigated the prevalence of Helicobacter Pylori infection amongst undergraduate students of Babcock University, Ilishan-Remo, Ogu n State, Nigeria. A total number of 200 students (85 males and 115 females) were screened using rapid serological methods. The prevalence of Helicobacter Pylori infection by serum antibody and stool antigen detection methods in relation to their social demographic characteristics is presented in Tables 1 and 2, respectively. Out of the 200 participants screened, $56(28.0 \%)$ were positive for Helicobacter Pylori serum antibody, while 47 (23.5\%) were positive for Helicobacter Pylori stool antigen. There was no significant difference $(\mathrm{P}>0.05)$ in the prevalence of Helicobacter Pylori infection among the study participants using

Table 1: Prevalence of Helicobacter pylori infection by serum antibody detection method in relation to social demographic characteristics of the study participants.

\begin{tabular}{|c|c|c|c|c|c|}
\hline Characteristics & Category & $\begin{array}{c}\text { Number of serum samples } \\
\text { examined }\end{array}$ & Number positive N (\%) & Number negative $\mathrm{N}(\%)$ & P-value \\
\hline \multirow{3}{*}{ Sex } & Male & 85 & $7(8.2)$ & $78(91.8)$ & 0.066 \\
\hline & Female & 115 & $49(42.6)$ & $66(57.4)$ & $* 0.042$ \\
\hline & Total & 200 & $56(28.0)$ & $144(72.0)$ & \\
\hline \multirow{5}{*}{ Age Range } & $16-20 \mathrm{Yrs}$ & 100 & $18(18.0)$ & $82(82.0)$ & 0.063 \\
\hline & $21-25$ Yrs & 93 & $37(39.8)$ & $56(60.2)$ & $* 0.004$ \\
\hline & 26-30 Yrs & 5 & $1(20.0)$ & $4(80.0)$ & 0.761 \\
\hline & $\geq 31$ Yrs & 2 & $0(0)$ & $2(100)$ & 0.585 \\
\hline & Total & 200 & $56(28.0)$ & $144(72.0)$ & \\
\hline \multirow{3}{*}{ Marital Status } & Single & 198 & $56(28.3)$ & $142(71.7)$ & $* 0.010$ \\
\hline & Married & 2 & $0(0)$ & $2(100)$ & 0.072 \\
\hline & Total & 200 & $56(28.0)$ & $144(72.0)$ & \\
\hline
\end{tabular}

both markers. Of the 85 male students tested, 7 (8.2\%) and 6 (7.1\%) were positive for serum antibody and stool antigen, respectively. $49(42.6 \%)$ out of the 115 female students tested were positive for serum antibody, while, 41 (35.7\%) were positive for stool antigen.

The prevalence of Helicobacter Pylori infection was found to be significantly higher $(\mathrm{P}<0.05)$ among female participants than their male counterparts (Tables $1 \& 2$ ). Based on age distribution, out of the 100 participants in the age group 16-20 years old, 18 and 14 of the students were positive for serum antibody and stool antigen, respectively. While out of the 93 participants in the age group of 21-25 years old, 37 (39.8\%) and 33 (35.5\%) students were positive for serum antibody and stool antigen, respectively. Only one of the $5(20.0 \%)$ participants in the age group 26-30 years old was seropositive for anti-Helicobacter Pylori antibody with no detectedable stool antigen. Interestingly, Helicobacter Pylori infection was not recorded in the age group 31 years and above. The two participants tested were found to be negative for both Helicobacter Pylori markers. The prevalence of Helicobacter Pylori infection was found to be significantly higher $(\mathrm{P}<0.05)$ among participants that were 21-25 years old when compared to other age groups (Tables $1 \& 2$ ). 


\begin{tabular}{|c|c|c|c|c|c|}
\hline \multirow{6}{*}{ Study Level } & 100 Level & 4 & $0(0)$ & $4(100.0)$ & 0.993 \\
\hline & 200 Level & 20 & $2(10.0)$ & $18(90.0)$ & 0.986 \\
\hline & 300 Level & 34 & $4(11.8)$ & 30 (88.2) & 0.757 \\
\hline & 400 Level & 84 & $22(26.2)$ & 62 (73.8) & $* 0.024$ \\
\hline & 500 Level & 58 & $28(48.3)$ & $30(51.7)$ & $* 0.006$ \\
\hline & Total & 200 & $56(28.0)$ & $144(72.0)$ & \\
\hline \multirow{4}{*}{ Religion } & Christianity & 180 & $51(28.3)$ & $129(71.7)$ & 0.416 \\
\hline & Islam & 16 & 3 (18.8) & 13 (81.2) & 0.694 \\
\hline & Traditional & 4 & $2(50.0)$ & $2(50.0)$ & 0.609 \\
\hline & Total & 200 & $56(28.0)$ & $144(72.0)$ & \\
\hline \multirow{5}{*}{ Tribe } & Yoruba & 119 & $43(36.1)$ & $76(63.9)$ & $* 0.014$ \\
\hline & Ibo & 39 & $6(15.4)$ & 33 (84.6) & 0.205 \\
\hline & Hausa & 2 & $2(100.0)$ & $0(0)$ & ${ }^{*} 0.011$ \\
\hline & Others & 40 & $5(12.5)$ & 35 (87.5) & 0.371 \\
\hline & Total & 200 & $56(28.0)$ & $144(72.0)$ & \\
\hline
\end{tabular}

*P value $<0.05$ is considered statistically significant

Table 2: Prevalence of Helicobacter pylori infection by stool antigen detection method in relation to social demographic characteristics of the study participants.

\begin{tabular}{|c|c|c|c|c|c|}
\hline Characteristics & Category & $\begin{array}{c}\text { Number of stool } \\
\text { samples examined }\end{array}$ & $\begin{array}{c}\text { Number positive } \\
\text { N (\%) }\end{array}$ & $\begin{array}{c}\text { Number negative } \\
\mathrm{N}(\%)\end{array}$ & P-value \\
\hline \multirow{3}{*}{ Sex } & Male & 85 & $6(7.1)$ & 79 (92.9) & 0.070 \\
\hline & Female & 115 & $41(35.7)$ & $74(64.7)$ & $* 0.048$ \\
\hline & Total & 200 & $47(23.5)$ & $153(76.5)$ & \\
\hline \multirow{5}{*}{ Age Range } & $16-20$ Yrs & 100 & $14(14.0)$ & $86(86.0)$ & 0.064 \\
\hline & $21-25$ Yrs & 93 & 33 (35.5) & $60(64.5)$ & $* 0.049$ \\
\hline & 26-30 Yrs & 5 & $0(0)$ & $5(100.0)$ & 0.776 \\
\hline & $\geq 30$ Yrs & 2 & $0(0)$ & $2(100.0)$ & 0.585 \\
\hline & Total & 200 & 47 (23.5) & $153(76.5)$ & \\
\hline \multirow{3}{*}{ Marital Status } & Single & 198 & 47 (23.7) & $151(76.3)$ & $* 0.011$ \\
\hline & Married & 2 & $0(0)$ & $2(100.0)$ & 0.077 \\
\hline & Total & 200 & $47(23.5)$ & $153(76.5)$ & \\
\hline \multirow{6}{*}{ Study Level } & 100 Level & 4 & $0(0)$ & $4(100.0)$ & 1.000 \\
\hline & 200 Level & 20 & $2(10.0)$ & $18(90.0)$ & 0.986 \\
\hline & 300 Level & 34 & $4(11.8)$ & $30(88.2)$ & 0.801 \\
\hline & 400 Level & 84 & $17(20.2)$ & $67(79.8)$ & $* 0.030$ \\
\hline & 500 Level & 58 & $24(41.4)$ & $34(58.6)$ & $* 0.006$ \\
\hline & Total & 200 & 47 (23.5) & $153(76.5)$ & \\
\hline \multirow{4}{*}{ Religion } & Christianity & 180 & $42(23.3)$ & 138 (76.7) & 0.416 \\
\hline & Islam & 16 & $3(18.8)$ & $13(81.2)$ & 0.700 \\
\hline & Traditional & 4 & $2(50)$ & $2(50)$ & 0.615 \\
\hline & Total & 200 & 47 (23.5) & $153(76.5)$ & \\
\hline \multirow{5}{*}{ Tribe } & Yoruba & 119 & $36(30.3)$ & 83 (69.7) & $* 0.020$ \\
\hline & Ibo & 39 & $6(15.4)$ & 33 (84.6) & 0.264 \\
\hline & Hausa & 2 & $2(100.0)$ & $0(0)$ & $* 0.018$ \\
\hline & Others & 40 & $3(7.5)$ & 37 (92.5) & 0.388 \\
\hline & Total & 200 & $47(23.5)$ & $153(76.5)$ & \\
\hline
\end{tabular}

$*$ P value $<0.05$ is considered statistically significant 
Furthermore, based on marital status, participants were either single or married. And out of the 198 singles tested, 56 (28.3\%) were positive for serum antibody, while 47 (23.7\%) were positive for stool antigen. None of the 2 married participants tested was positive for both Helicobacter Pylori serum antibody and stool antigen (Tables $1 \& 2$ ). Based on study level distribution, the infection was found in all study levels screened, except 100 levels (0\%). The highest occurrence of Helicobacter Pylori serum antibody and stool antigen was found among the 500 level students, $48.3 \%$ and $41.4 \%$, respectively; followed by those of $400(26.2 \%$ and 20.2\%), 300 (11.8\% and 11.8\%) and 200 (10\% and 10\%) level. The number of 500 level students with Helicobacter Pylori infection were significantly higher $(\mathrm{P}<0.05)$ than those of 200 and 300 level; howbeit, there was no significant difference $(\mathrm{P}>0.05)$ between the number of 400 level students who were positive when compared to those of 500 level students (Tables $1 \& 2$ ).

On the basis of religion, out of the 180 Christian students that participated in the study, 51 (28.3\%) were positive for Helicobacter Pylori serum antibody, while $42(23.3 \%)$ were positive for the stool antigen. On the other hand, 3 (18.8\%) out of the 16 Muslim participants tested were found to be positive for both Helicobacter Pylori serum antibody and stool antigen. The outcome of the study also show that $2(50 \%)$ out of the 4 Traditional worshippers tested were found to be positive for the both Helicobacter Pylori infection markers. In all, there was no significant difference $(\mathrm{P}>0.05)$ in the prevalence of Helicobacter Pylori infection among the study participants on the basis of religion (Tables 1 \& 2). On the basis of tribal differences, records show that, out of the 119 Yoruba students tested, 43 (36.1\%) were found to be positive for Helicobacter Pylori serum antibody, while $36(30.3 \%)$ tested positive for the stool antigen.

On the other hand, 6 (15.4\%) out of the 39 Ibo students tested positive for both Helicobacter Pylori serum antibody and stool antigen. The only $2(100 \%)$ Hausa students in the study tested positive for both Helicobacter Pylori infection markers. 5 (12.5\%) out of the 40 students categorized as other tribes were positive for serum antibody, while only $3(7.5 \%)$ were positive for the stool antigen. The prevalence of Helicobacter Pylori infection was found to be significantly higher $(\mathrm{P}<0.05)$ among Yoruba students than among other tribes who were neither Ibo nor Hausa. Also, the prevalence of Helicobacter Pylori infection was significantly higher $(\mathrm{P}<0.05)$ among Hausa students, than in Ibos and other tribes, except the Yoruba's (Tables 1\&2).

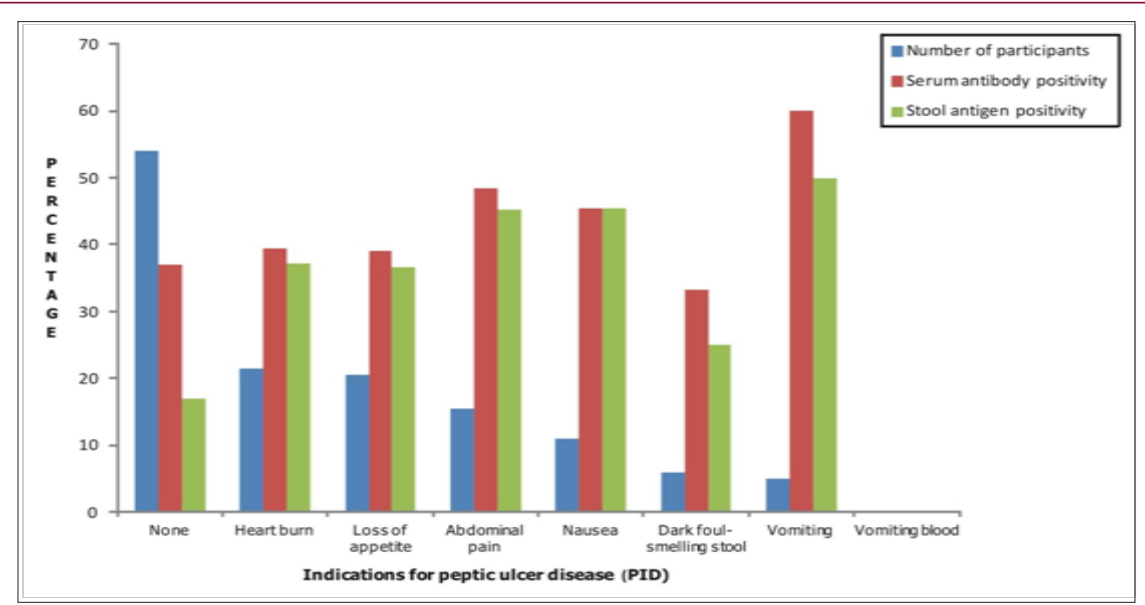

Figure 3: Histogram showing the relationship between indications for Peptic ulcer disease and Helicobacter pylori serum antibody and stool antigen positivity among the study participants.

The relationship between indications for Peptic ulcer disease and Helicobacter Pylori serum antibody and stool antigen positivity among the study participants is presented using a bar chart (Figure 3). On one hand, 108 (54.0\%) of the participants were asymptomatic, out of which $20(37.0 \%)$ of them were positive for Helicobacter Pylori serum antibody, while 18 (17.0\%) were positive for the stool antigen. Symptomatic participants on the other hand, complained mostly of heart burn, followed by loss of appetite, abdominal pain, nausea, dark foul-smelling stool and lastly, vomiting. Howbeit, none of them complained of vomiting blood. Out of the $43(21.5 \%)$ participants that indicated heart burn, 17 (39.5\%) and $16(37.2 \%)$ of them were positive for Helicobacter Pylori serum antibody and stool antigen, respectively. Also, out of $41(20.5 \%)$ participants that indicated loss of appetite, 16 (39.0\%) and 15 (36.6\%) of them were positive for Helicobacter Pylori serum antibody and stool antigen, respectively.
Abdominal pain was present only in $31(15.5 \%)$ cases, out of which, $15(48.4 \%)$ of them were positive for Helicobacter Pylori serum antibody, while $14(45.2 \%)$ were positive for stool antigen. 10 (45.5\%) out of the $22(11.0 \%)$ participants who indicated nausea, were both positive for the Helicobacter Pylori infection markers. Four $(33.3 \%)$ out of the $12(6.0 \%)$ participants that indicated dark foul-smelling stool tested positive for Helicobacter Pylori serum antibody, while only 3 (25.0\%) tested positive for the stool antigen.

Vomiting was present in 10 (5.0\%) participants, 6 (60.0\%) out of which were positive for Helicobacter Pylori serum antibody, while $5(50.0 \%)$ were positive for the stool antigen. The distribution of Helicobacter Pylori serum antibody and stool antigen positivity of the study participants in relation to risk factors is presented in Table 3. Out of the 9 respondents who had past history of H. pylori infection, 4 (44.4\%) of them were both positive for serum antibody and stool antigen. 
Table 3: Distribution of Helicobacter pylori serum antibody and stool antigen positivity of the study participants in relation to risk factors.

\begin{tabular}{|c|c|c|c|c|}
\hline Characteristics & Responses & Number of participants & Serum antibody positivity N (\%) & Stool antigen positivity $\mathrm{N}(\%)$ \\
\hline \multirow{2}{*}{$\begin{array}{l}\text { Past history of H. pylori } \\
\text { infection }\end{array}$} & Yes & 9 & $4(44.4)$ & $4(44.4)$ \\
\hline & No & 191 & $52(27.2)$ & $43(22.5)$ \\
\hline \multirow{2}{*}{$\begin{array}{l}\text { Past history of gastric } \\
\text { diseases }\end{array}$} & Yes & 38 & $14(36.8)$ & $13(34.2)$ \\
\hline & No & 162 & $42(25.9)$ & $34(21.0)$ \\
\hline \multirow{2}{*}{$\begin{array}{l}\text { Past history of abdominal } \\
\text { surgery }\end{array}$} & Yes & 10 & $0(0)$ & $0(0)$ \\
\hline & No & 190 & $56(29.5)$ & $47(24.7)$ \\
\hline \multirow{2}{*}{ Drink coffee } & Yes & 87 & $27(31.0)$ & $22(25.3)$ \\
\hline & No & 113 & $29(25.7)$ & $25(22.1)$ \\
\hline \multirow{2}{*}{ Drink raw cow milk } & Yes & 10 & $2(20.0)$ & $2(20.0)$ \\
\hline & No & 190 & $54(28.4)$ & 45 (23.7) \\
\hline \multirow{2}{*}{ Consume beef } & Yes & 185 & $53(28.7)$ & $44(23.8)$ \\
\hline & No & 15 & $3(20.0)$ & $3(20.0)$ \\
\hline \multirow{2}{*}{ Consume fish } & Yes & 190 & $54(28.4)$ & $45(23.7)$ \\
\hline & No & 10 & $2(20.0)$ & $2(20.0)$ \\
\hline \multirow{2}{*}{$\begin{array}{l}\text { Consume poultry/Poultry } \\
\text { products }\end{array}$} & Yes & 188 & $54(28.7)$ & 45 (23.9) \\
\hline & No & 12 & $2(16.7)$ & $2(16.7)$ \\
\hline \multirow{2}{*}{$\begin{array}{l}\text { Consume vegetables and } \\
\text { fruits }\end{array}$} & Yes & 196 & $56(28.6)$ & 47 (24.0) \\
\hline & No & 4 & $0(0)$ & $0(0)$ \\
\hline \multirow{2}{*}{$\begin{array}{l}\text { Collected garbage in the } \\
\text { neighbourhood as a child }\end{array}$} & Yes & 47 & $11(23.4)$ & $9(19.1)$ \\
\hline & No & 153 & $45(29.4)$ & $38(24.8)$ \\
\hline \multirow{2}{*}{$\begin{array}{l}\text { Collected garbage in the } \\
\text { neighbourhood as an adult }\end{array}$} & Yes & 21 & $3(14.3)$ & $3(14.3)$ \\
\hline & No & 179 & $53(29.6)$ & $44(24.6)$ \\
\hline \multirow{3}{*}{$\begin{array}{c}\text { Type of water drank as a } \\
\text { child }\end{array}$} & Portable & 79 & $17(21.5)$ & $11(13.9)$ \\
\hline & $\begin{array}{c}\text { Boiled or } \\
\text { Filtered }\end{array}$ & 80 & $25(31.3)$ & $25(31.3)$ \\
\hline & $\begin{array}{l}\text { Not boiled or } \\
\text { filtered }\end{array}$ & 49 & $14(28.6)$ & $15(30.6)$ \\
\hline \multirow{3}{*}{$\begin{array}{c}\text { Type of water drank as an } \\
\text { adult }\end{array}$} & Portable & 98 & $25(25.5)$ & 19 (19.4) \\
\hline & $\begin{array}{l}\text { Boiled or } \\
\text { Filtered }\end{array}$ & 63 & $21(33.3)$ & $20(31.8)$ \\
\hline & $\begin{array}{l}\text { Not boiled or } \\
\text { filtered }\end{array}$ & 39 & $10(25.6)$ & $10(25.6)$ \\
\hline
\end{tabular}

Thirty eight (38) of the respondents indicated past history of gastric diseases, out of which, $14(36.8 \%)$ were positive for serum antibody and $13(34.2 \%)$ for the stool antigen. None of the $10(0 \%)$ respondents who indicated past history of abdominal surgery were positive for $H$. pylori infection. Out of the 87 respondents that indicated that they drink coffee, 27(31.0\%) were positive for serum antibody and 22(25.3\%) for the stool antigen while out of the 113 respondents that indicated that they don't drink coffee, $29(25.7 \%)$ were positive for serum antibody, whereas 25(22.1\%) were positive for the stool antigen. Furthermore; 2 (20\%) out of the 10 respondents who indicated that they drink raw cow milk were both positive for H. pylori serum antibody and stool antigen. 53 (28.7\%) out of the 185 respondents who consume beef tested positive for H. pylori serum antibody, while $44(23.8 \%)$ tested positive for the stool antigen. $54(28.4 \%)$ of the 190 respondents who indicated that they consume fish were found positive for H. pylori serum antibody, while $45(23.7 \%)$ were positive for the stool antigen. 54 (28.7\%) of the 188 respondents who indicated consumption of poultry/poultry products were found positive for $H$. pylori serum antibody, while 45 (23.9\%) were positive for the stool antigen.

Interestingly, 56 (28.6\%) out of 196 respondents who indicated that they consume vegetables and fruits tested positive for $H$. pylori serum antibody, while 47 (24.0\%) were positive for the stool antigen (Table 3). With regards to the type of water drank as a child, 79 respondents indicated that they drank portable water, out of which $17(21.5 \%)$ were positive for $H$. pylori serum antibody, while 11 (13.9\%) were positive for the stool antigen. 25 (31.3\%) out of the 80 who indicated consumption of boiled or filtered water as a child, tested positive for both $H$. pylori infection markers. 14 (28.6\%) out of the 49 respondents who drank "not boiled or filtered water" tested positive for H. pylori serum antibody, while 15 (30.6\%) were positive for the stool antigen. Still, out of the 98 respondents who 
drink portable water as adult, 25 (25.5\%) of them were positive for serum antibody, while 19 (19.4\%) were positive for stool antigen. 63 of the respondents indicated that they drank boiled or filtered water, out of which 21 (33.3\%) and 20 (31.8\%) were positive for $H$. pylori serum antibody and stool antigen, respectively. And finally, $10(25.6 \%)$ out of the 39 respondents, who drink "not boiled or filtered water", were found to be positive for both H. pylori serum antibody and stool antigen.

\section{Discussion}

H. pylori infection has been identified as an important risk factor for the development of peptic ulcer disease (PUD) and is probably the most important cause of relapse in those previously treated for peptic ulcer disease [4]. Here in Babcock University, to the best of our knowledge, no data on the prevalence of $H$. pylori infection and associated risk factors exist. This present work was therefore designed to determine the prevalence of Helicobacter Pylori infection and associated risk factors among undergraduate students of Babcock University, Ilishan-Remo, Ogun State. A total number of 200 students ( 85 males and 115 females) were screened using rapid serological methods which are considered to be the most feasible means of determining the population epidemiology of $H$. pylori against the invasiveness of specimen collection for bacteriologic diagnosis and the expense of tests such as labelled urea breath test. Out of the 200 participants screened, 56 (28.0\%) were positive for Helicobacter Pylori serum antibody, while 47 (23.5\%) were positive for Helicobacter Pylori stool antigen. There is no significant difference in the prevalence of Helicobacter Pylori infection among the study participants using both serological markers.

On one hand, the result obtained in this study is higher than those of previous studies by Jemikalajah and Okogun [3] and Moujaber et al. [13], who reported a prevalence rate of $12.7 \%$ and $15.4 \%$ among a study population in Nigeria and Australia, respectively using serum antibody tests. While, on the other hand, the prevalence rate observed in this present study is lower than that of Al Faleh et al. [14,15] and Bastos et al. [16] who reported a prevalence rate of $47.0 \%, 71.7 \%$ and $84.2 \%$, among a study population in Saudi Arabia, China and Portugal, respectively using serum antibody tests as well. The present result for stool antigen test $(23.5 \%)$ is far lower than the $84.0 \%$ reported by Cherian et al. [17], among African refugee children from resettlement in Australia. This is not surprising, because overcrowding has been noted as a risk factor for the transmission of Helicobacter Pylori infection.

It is interesting to note that the prevalence rate of serum antibody to $H$. pylori observed in this current study $(28.0 \%)$ is comparable with the $28.3 \%$ reported by Hanafi and Mohamed [18] among healthy individuals in Saudi Arabia. Of the 85 male students tested, $7(8.2 \%)$ and $6(7.1 \%)$ were positive for serum antibody and stool antigen, respectively. While $49(42.6 \%)$ out of the 115 female students tested were positive for serum antibody; 41 (35.7\%) were positive for stool antigen. The prevalence of Helicobacter Pylori infection was found to be significantly higher among female participants than their male counterparts. More female than male participants indicated past history of Helicobacter Pylori infection and other gastric diseases. They also noted to have symptoms of abdominal pain and heart burn than the male participants. This could be due to the over-intake of coffee than their male counterparts as indicated in their completed questionnaires. Coffee contains caffeine which also increases the volume and concentration of stomach acid and can worsen an existing ulcer. Though, increase in stomach acid levels is not due to caffeine only but can be partnered with H. pylori, smoking and drinking alcohol.

This present study agrees with that of Zhu et al. [19], who also reported a significant difference between male (61.74\%) and female (64.47\%) using urea breath test. Also, a study by Jemikalajah and Okogun [3], reported a higher prevalence in females than males, $8.1 \%$ and $4.6 \%$ respectively using serological method. However, in a test of association between sex and infection rate using serology, Nwodo et al. [5] showed that H. pylori infection has no significant association with sex ( $p>0.05$ ). Previous studies by Eusebi et al. [20], also shows that there was no significant difference in the prevalence rate of $H$. pylori infection between men and women using the same method. On the basis of age distribution, the outcome of this study shows that $H$. pylori infection was more prevalent among participants 21-25 years old than in other age groups examined. This study differs from other previous studies that reported high prevalence rate of $H$. pylori infection mostly in the elderly. According to Eusebi et al. [20], studies from Morocco and Ethiopia reported a prevalence of $H$. pylori infection of $75.5 \%$ [21] and 65.7\% [22], respectively. Both studies found a significant increase with age.

A survey from Nigeria also reported a prevalence rate of $80 \%$ and $93.6 \%$ among the elderly using histological and serological methods, respectively [23]. Calvet et al. [24], on the other hand, reported a very high prevalence of infection among Portugese children around the age of 13 years old. But, according to Eusebi et al. [20], lower prevalence of infection in the younger generations would suggest a further decline in $H$. pylori prevalence in the community over the decade. This current study cannot prove whether H. pylori infection is predominant in children, young adult or elderly, as it focused mainly on the undergraduate students, of which most of them are in their early twenties and two [2] in their early thirties. With regard to the tribal distribution, data obtained show that Helicobacter Pylori infection was significantly higher $(\mathrm{P}<0.05)$ among Yoruba students than among other tribes who were neither Ibo nor Hausa. It was also significantly higher $(\mathrm{P}<0.05)$ among Hausa students, than in Ibos and other tribes, except the Yorubas.

Most of the Yoruba participants who tested positive indicated the following risk factors: past history of $H$. pylori infection and gastric diseases, consumption of beef, poultry products, vegetables and fruits among several others. $H$. pylori has been discovered to be zoonotic in nature, so, consumption of animal products such as beef that is not properly cooked which is infected with $H$. pylori serve as a source of $H$. pylori infection. A study by Atapoor et al. [25], reported the presence of $H$. pylori in vegetables due to their close contact with polluted water, soil and feces. A total of 460 vegetable 
and salad samples were collected and result showed that 44 of 460 samples were positive for $H$. pylori using the culture method while 50 of 460 samples were positive using Polymerase Chain Reaction (PCR). Furthermore, the only two Hausa participants in the study, who also tested positive, were noted to have taken raw cow milk in addition to other risk factors they indicated. Previous studies reports that animals such as cow serve as a reservoir for $H$. pylori. Though milk provides brief relief of ulcer pain because it covers the stomach lining, also milk has been noted to increase acid secretion in the stomach, and may increase the risk of ulcers and indigestions.

A study by Briffa [26], reported that in the mid-seventies, Researchers questioned the practice of drinking milk to relieve ulcer pains and they discovered it actually increases stomach acid secretion and further research in the eighties suggested that milk actually delays the healing of duodenal ulcers. From this study, the prevalence of $H$. pylori infection among the study participants appear not to be connected with the consumption of a particular type of water (i.e., boiled or filtered water, not boiled nor filtered water and portable water), as some of them who drink either of these types of water still tested positive to the serum antibody and stool antigen. But according to Mhaskar et al. [27], participants who did not drink filtered or boiled water were more likely to suffer from H. pylori infection compared with individuals who drank filtered or boiled water. It is important to mention here that the isolation of H. pylori from municipal treated drinking water in Iraq has been reported by Al-Sulami et al. [28]. Also, Moreno and Ferrus [29] claimed the isolation of $H$. pylori from five treated water samples, of which 14 samples were positive by PCR. Furthermore, the result of this study also suggests that a relationship between indications of peptic ulcer disease and Helicobacter Pylori exist.

For instance, out of the $43(21.5 \%)$ participants that indicated heart burn, 17 (39.5\%) and $16(37.2 \%)$ of they were positive for Helicobacter Pylori serum antibody and stool antigen, respectively. Abdominal pain was present only in 31 (15.5\%) cases, out of which, $15(48.4 \%)$ of them were positive for Helicobacter Pylori serum antibody, while 14 (45.2\%) were positive for stool antigen. Also, $4(33.3 \%)$ out of the $12(6.0 \%)$ participants that indicated dark foul-smelling stool tested positive for Helicobacter Pylori serum antibody, while only 3 (25.0\%) tested positive for the stool antigen. The above agrees with the findings from previous studies. Nwodo et al. [5] in particular reported a prevalence rate of $22.2 \%$ of $H$. pylori infection among patients with gastritis and PUD in Kaduna state using serological method; while Adeniyi et al. [10], reported that almost $100 \%$ cases of duodenal ulcer and $82 \%$ cases of gastric ulcer are H. pylori positive. Their work showed that $81.4 \%$ of patients with gastric ulcer examined were infected with $H$. pylori using urea breath test, histology and culture.

Fashner and Gitu [8], reported gastrointestinal perforation and bleeding as complications in H. pylori positive patients. Some of the participants who had past history of $H$. pylori infection and gastric diseases tested positive to both serum antibody and stool antigen but interestingly, none of the participants who indicated past history of abdominal surgery were positive for $H$. pylori infection. This current study was unable to confirm history of abdominal surgery as a risk factor for $H$. pylori infection as previously reported. This will require more investigation in the future. In this study, some of the participants tested positive to the serum antibody, but negative for stool antigen, while some tested positive for both serum antibody and stool antigen. Still, some tested negative for both serum antibody and stool antigen. The implication of this is, those that tested positive for only serum antibody and not stool antigen must have been immunized due to past exposure to $H$. pylori (past infection); hence the reason for the presence of antibody to H. pylori in their serum. Those that were positive to both serum antibody and stool antigen are having a current infection while those that were negative to both serum antibody and stool antigen are susceptible to H. pylori infection.

\section{Conclusion}

The results obtained in this study prove that $H$. pylori infection is present among undergraduate students of Babcock University with a prevalence rate of $28.0 \%$ and $23.5 \%$ using serum antibody and stool antigen tests, respectively. Identifiable risk factor associated with infection include: past history of $H$. pylori infection/gastric diseases, drinking of raw cow milk, consumption of beef, fish, poultry products, vegetables and fruits among several others.

\section{References}

1. Christopher JA, Abiodun AJ, Olawale OS, Abideen OO, Adegboyega A (2010) Prevalence of Helicobacter Pylori among Nigerian Patients with Dyspepsia in Ibadan. Pan Afr Med J 6(1): 18.

2. Mynepalli SKC, Maureen O, Mumuni A (2014) Prevalence of Helicobacter pylori and Hygiene Practices among Public Secondary School Students in Ikeja Local Government Area. Health 6(4): 250-258.

3. Jemikalajah DJ, Okogun GRA (2014) Health Point Prevalence of Helicobacter pylori in Central Hospital Warri, Nigeria. African Journal of the Cellular Pathology 3(1): 57-60.

4. Tijjani B, Umar A (2008) Peptic Ulcer Disease and Helicobacter Infection at Kano, Nigeria. The Internet Journal of Gastroenterology 8(1): 1-4.

5. Nwodo EN, Yakubu SE, Jatau ED, Yabaya A (2009) Seroprevalence of Helicobacter pylori Infection in Patients with Gastritis and Peptic Ulcer Disease in Kaduna, African Journal of Basic and Applied Sciences 1(5-6): 123-128.

6. Higuera V (2005) Peptic Ulcer, Healthline 1(1): 3-5.

7. Mustafa M, Menon J, Muiandy RK, Fredie R, Sein MM, et al. (2015) Risks Factors, Diagnosis, and Management of Peptic Ulcer Disease. Journal of Dental and Medical Sciences 14(7): 40-46.

8. Fashner J, Gitu CA (2015) Diagnosis and Treatment of Peptic Ulcer Disease and H. pylori Infection, American Family Physician 91(4): 236242.

9. Kusters JG, Arnoud HM, Kuipers EJ (2006) Pathogenesis of Helicobacter Pylori Infection. Clin Microbiol Rev 19(3): 449-490.

10. Adeniyi BA, Otegbayo JA, Lawal TO, Oluwasola AO, Odaibo GN, et al. (2012) Prevalence of Helicobacter pylori Infection among Dyspepsia Patients in Ibadan, African Journal of Microbiology Research 6(14): 3399-3402.

11. Ejilude OA, Akinduti PA, Umaihon KO (2000) Seroprevalence of Helicobacter pylori IgG in Patients with Symptomatic Peptic Ulcer. Journal of Medical Laboratory Science 18(1): 29-35.

12. Shott S (1990) Statistics for Health Professionals. Saunders WB, Co Philadelphia, USA, pp. 313-336. 
13. Moujaber T, Maclntyre CR, Backhouse J, Gidding H, Quinn H, et al. (2008) The Seroepidemiology of Helicobacter pylori Infection in Australia. International Journal of Infectious Diseases 1(12): 500-504.

14. Al Faleh FZ, Ali S, Aljebreen AM, Alhammad E, Abdo AA (2010) Seroprevalence Rates of Helicobacter pylori and Viral Hepatitis A among Adolescents in Three Regions of the Kingdom of Saudi Arabia: is there any correlation? Helicobacter 15(6): 532-537.

15. Li Z, Zou D, Ma X, Chen J, Shi X et al. (2010) Epidemiology of Peptic Ulcer Disease: Endoscopic Results of the Systematic Investigation of Gastrointestinal Disease in China. Am J Gastroenterol 105(12): 25702577.

16. Bastos J, Peleteiro B, Barros R (2013) Sociodemographic Determinants of Prevalence and Incidence of Helicobacter pylori Infection in Portugese adults. Helicobacter 18(6): 413-422.

17. Cherian S, Burgner DP, Cook AG, Sanfilippo FM, Forbes DA (2010) Associations between Helicobacter pylori Infection, Co-morbid Infections, Gastrointestinal Symptoms and Circulating Cytokines in African children. Helicobacter 15(2): 88-97.

18. Hanafi MI, Mohamed AM (2013) Helicobacter pylori Infection: Seroprevalence and Predictors among Healthy Individuals in Al Madinah, Saudi Arabia. J Egypt Public Health Assoc 88(1): 40-45.

19. Zhu Y, Zhou X, Wu J, Su J, Zhang G (2014) Risk Factors and Prevalence of Helicobacter pylori Infection in Persistent High Incidence Area of Gastritic Carcinoma in Yangzhong city. Gastroenterology Research and Practice 5(14): 10

20. Eusebi LH, Zagari RM, Bazzoli F (2014) Epidemiology of Helicobacter pylori Infection. Helicobacter 19(1): 1-5.

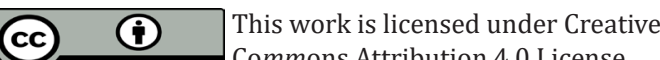

Submission Link: https://biomedres.us/submit-manuscript.php
21. Benajah DA, Lahbabi M, Alaoui S, El Rhazi M, Nejjari C, et al. (2013) Prevalence of Helicobacter pylori and its recurrence after successful eradication in a developing nation (Morocco). Clin Res Hepatol Gastroenterol 37(5): 519-526.

22. Mathewos B, Moges B, Dagnew M (2013) Seroprevalence and Trend of Helicobacter pylori Infection in Gondar University Hospital among Dyspeptic Patients, Gondar, North West Ethiopia. BMC Res Notes 1(6): 346.

23. Olokoba AB, Gashau W, Bwala S, Adamu A, Salawu FK (2013) Helicobacter pylori Infection in Nigerians with Dyspepsia. Ghana Med J 47(2): 79-81.

24. Calvet X, Lazaro MR, Lehours P, Megraud F (2013) Diagnosis and Epidemiology of Helicobacter pylori Infection. Helicobacter 18(1): 5-11.

25. Atapoor S, Dehkordi FS, Rahimi E (2014) Detection of Helicobacter pylori in Various Types of Vegetables and Salads. Jundishapur Journal of Microbiology 7(5): 10013.

26. Briffa J (2001) Why Milk is not the Answer for Stomach Ulcers. Health 1(1): 1.

27. Mhaskar RS, Ricardo I, Azliyati A, Laxminarayan R, Amol B, et al. (2013). Assessment of Risk Factors of Helicobacter pylori Infection and Peptic Ulcer Disease. Journal of Global Infectious Diseases 5(2): 60-67.

28. Al-Sulami AA, Al-Taee AMR, Juma'a MG (2010) Isolation and Identification of Helicobacter pylori from drinking water in Basra Governorate, Iraq. Eastern Mediterranean Health Journal 16(9): 920-925.

29. MorenoY, Ferrus MA (2012) Specific Detection of Cultivable Helicobacter pylori Cells from Wastewater Treatment Plants. Helicobacter 17(5): 327 332.

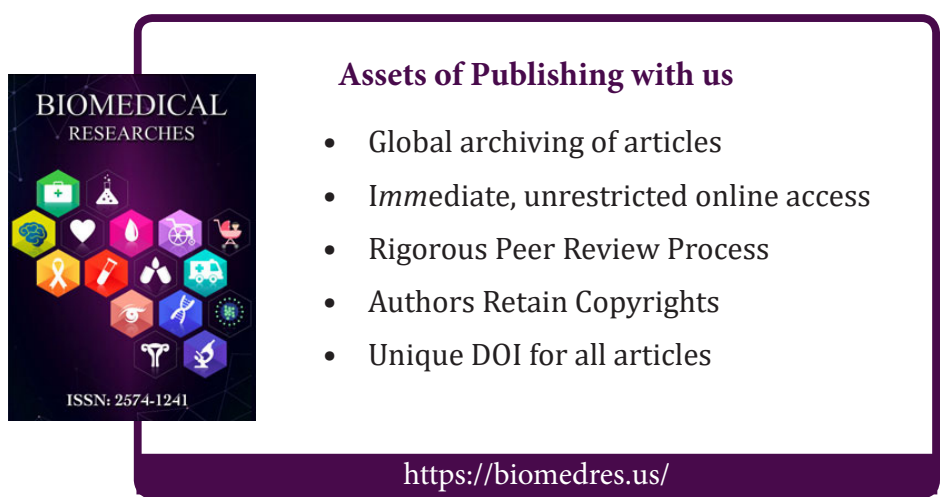

